JPP 2002, 54: 1423-1427

(C) 2002 The Authors

Received March 5, 2002

Accepted July 5, 2002

ISSN 0022-3573
Department of Pharmacology, Faculty of Pharmacy, University of Seville, C/ Profesor Garcla González s/n, 41012-Seville, Spain

Marla Dolores Herrera, Rosario Bueno, Marra Alvarez de Sotomayor, Concepción PérezGuerrero, Elisa Marhuenda

Department of Physiology and Animal Biology, Faculty of Pharmacy, University of Seville, C/ Profesor Garcla González s/n, 41012-Seville, Spain

Carmen M. Vázquez

Correspondence: M. D. Herrera, Department of Pharmacology, Faculty of Pharmacy, University of Seville, C/ Profesor Garcla González s/n, 41012-Seville, Spain. E-mail:

herrera@fafar.us.es

\section{Endothelium-dependent vasorelaxation induced by L-carnitine in isolated aorta from normotensive and hypertensive rats}

\author{
María Dolores Herrera, Rosario Bueno, María Alvarez de Sotomayor, \\ Concepción Pérez-Guerrero, Carmen M. Vázquez and Elisa Marhuenda
}

\begin{abstract}
The aim of this work was to investigate the mechanism of the vasodilatory effect induced by Lcarnitine. Relaxation produced by L-carnitine was studied in rat aortic rings with and without functional endothelium, pre-contracted with phenylephrine by adding cumulative doses of Lcarnitine $\left(10^{-7}\right.$ to $\left.10^{-3} \mathrm{M}\right)$. The relaxation evoked by L-carnitine reached higher values in aortic rings from spontaneously hypertensive rats than those obtained in arteries from normotensive rats; no relaxation was produced in de-endothelialized arteries. However, in the presence of $N^{G}$-nitro-Larginine $\left(3 \times 10^{-5} \mathrm{M}\right.$, a nitric oxide synthase inhibitor), Ro $68070\left(10^{-4} \mathrm{M}\right.$, a thromboxane synthetase inhibitor-thromboxane $\mathrm{A}_{2}$ /prostaglandin $\mathrm{H}_{2}$ receptor antagonist) or $\mathrm{ICI} 192605$ ( $10^{-5} \mathrm{M}$, a thromboxane $\mathrm{A}_{2}$ receptor antagonist) the relaxant response to L-carnitine was significantly inhibited. These results show that L-carnitine induced endothelium-dependent relaxation in the rat aorta and the mechanism of this relaxation appeared to be mostly mediated by endothelial production of nitric oxide but also could involve prevention of the action of cyclooxygenase endothelial products acting on the thromboxane $A_{2}$ /prostaglandin $\mathrm{H}_{2}$ receptor.
\end{abstract}

\section{Introduction}

L-Carnitine and its derivates have received increasing attention, mainly because of their beneficial effects on ischaemic tissues (Bartels et al 1995; Tatlican et al 1998), and are being used in a spectrum of diseases including multiple cardiovascular conditions (Arsenian 1997). Carnitine has useful properties in some cardiovascular pathologies such as heart failure (Mancini et al 1992; Sethi et al 1999), angina pectoris (Bartels et al 1994; Mondillo et al 1995) and arrhythmias (Rizzon et al 1989). In the same way, Lcarnitine has been shown to be useful in patients with essential hypertension and diabetes (Digiesi et al 1989), because it was able to improve the left ventricle function and to induce lowering of some fractions of serum lipids (Digiesi et al 1994). Therefore, L-carnitine might prevent some cardiovascular alterations by its influence on lipid metabolism (Rauchová et al 1998). Despite most published data on carnitine and its derivates being favourable, clinical trials have been relatively scanty and the mechanism by which the function during ischaemia is improved is not fully known. An unknown mechanism of action is implicated in improving the walking capacity in patients with peripheral vascular disease (Brevetti et al 1992) and alternative mechanisms, independent of the classical metabolic pathways, have been proposed to explain the beneficial effects of these compounds (Fritz et al 1993).

The objective of this study was to investigate the possible vasoactive effects of Lcarnitine in isolated aorta from spontaneously hypertensive rats and to determine the contribution of the endothelium to mediating these vasodilatory effects. 


\section{Materials and Methods}

\section{Chemical reagents and drugs}

L-carnitine, acetylcholine chloride, indometacin, $N^{\mathrm{G}}$-nitroL-arginine (L-NOARG), noradrenaline (norepinephrine) bitartrate, phenylephrine hydrochloride and trans-2phenylcyclopropyl-amine (tranylcypromine) were purchased from Sigma Chemical Co (St Louis, MO). ICI 192,605 was from Tocris (Biogen Cientifica S.L. Spain). Ridogrel (Ro-68070) was generously provided by Janssen Pharmaceutical (Beerse, Belgium). The drugs were dissolved in distilled water, except indometacin and ICI 192,605 which were dissolved in dimethyl sulfoxide (DMSO); stock solutions were prepared at $10^{-2} \mathrm{M}$ concentration. The final concentration of DMSO in the tissue bath was less than $0.1 \%$, which was shown to have no effect on the basal tonus of the preparation. All concentrations of the drugs used are expressed as final concentration in the organ chamber.

\section{Animals}

Male spontaneously hypertensive rats (SHR) and normotensive Wistar Kyoto (WKY) rats, 10-12 weeks old, weighing $250-300 \mathrm{~g}$, were housed at $24 \pm 2{ }^{\circ} \mathrm{C}$ with $60 \pm 20 \%$ relative humidity, on a 12-h light-dark cycle. Rats were given free access to a diet of standard chow and water. SHR with systolic pressure (SBP) higher than $170 \mathrm{mmHg}$ were used in the experiments. All experiments were performed according to the guidelines for the ethical treatment of animals of the European Union. The rats were killed by cervical dislocation and the aortae were rapidly dissected.

\section{Aortic ring preparation}

The descending thoracic aorta was placed in a modified Krebs-Henseleit solution (PSS) containing (mM): $\mathrm{NaCl}$ $118, \mathrm{KCl} 4.75, \mathrm{NaHCO}_{3} 25, \mathrm{MgSO}_{4} 1.2, \mathrm{CaCl}_{2} 1.8, \mathrm{KH}_{2} \mathrm{PO}_{4}$ 1.2 and glucose 11. After excess fat and connective tissue were removed, the aortae were cut into $2-3-\mathrm{mm}$ rings. Aortic rings were mounted under a basal tension of $2 \mathrm{~g}$ in 20-mL organ baths containing PSS and attached to an isometric transducer (Harvard UF-1); the signal was recorded by a Powerlab data acquisition system (AD-Instruments). The tissue bath was maintained at $37^{\circ} \mathrm{C}$ and bubbled with a $95 \% \mathrm{O}_{2}-5 \% \mathrm{CO}_{2}$ gas mixture. In some experiments, the endothelium was mechanically removed by gently rubbing the intimal surface. The absence of endothelium was confirmed by the absence of relaxing effects of acetylcholine $\left(10^{-6} \mathrm{M}\right)$ in aortic rings previously contracted by noradrenaline (norepinephrine) $\left(10^{-5} \mathrm{M}\right)$. Each preparation was allowed to equilibrate for at least $90 \mathrm{~min}$ before initiation of experimental procedures, and during this period the incubation medium was changed every 20 min (Alvarez de Sotomayor et al 2001).

\section{Relaxant effect of L-carnitine}

The relaxant effect of L-carnitine was assessed by adding cumulative concentrations of this drug $\left(10^{-7}\right.$ to $\left.10^{-3} \mathrm{M}\right)$ to aortic rings precontracted by phenylephrine $\left(3 \times 10^{-7} \mathrm{M}\right.$ in WKY rats or $10^{-6} \mathrm{M}$ in SHR). This experiment was carried out in both intact and endothelium-denuded arteries.

To analyse the influence of endothelial factors, vessels were incubated for $30 \mathrm{~min}$ with L-NOARG $\left(3 \times 10^{-5} \mathrm{M}\right.$, an inhibitor of nitric oxide synthesis), indometacin $\left(10^{-5} \mathrm{M}\right.$, to inhibit prostaglandin production), tranylcypromine $\left(10^{-4} \mathrm{M}\right.$, a PGI 2 inhibitor $)$, ICI $192,605\left(10^{-5} \mathrm{M}\right.$, a thromboxane $\mathrm{A}_{2}$ receptor antagonist) or ridogrel (Ro-68070; a thromboxane synthetase inhibitor-thromboxane $\mathrm{A}_{2} /$ prostaglandin $\mathrm{H}_{2}$ receptor antagonist) $\left(10^{-4} \mathrm{M}\right)$ which were added to the bath $60 \mathrm{~min}$ before the response to phenylephrine was tested. Different aortic rings were used in each experiment. After incubation, aortae were contracted with phenylephrine $\left(3 \times 10^{-7} \mathrm{M}\right.$ or $\left.10^{-6} \mathrm{M}\right)$ and when the contractile response was reached, L-carnitine $\left(10^{-7}\right.$ to $10^{-3} \mathrm{M}$ ) was tested by adding cumulative doses every $15 \mathrm{~min}$, in the presence of these different inhibitors. All the results were expressed as a percentage of the maximal contraction of phenylephrine-induced responses.

\section{Statistical analysis}

Results are expressed as percentages from the initial precontraction level and as means \pm s.e.m $(n=6$ rats). Eight preparations were studied from a single aorta. Analysis of variance and Tukey's multiple comparison test were used for statistical analysis. $P<0.05$ values were considered to represent a significant difference. All curves were fitted by a concentration-response non-linear regression equation.

\section{Results}

\section{Relaxation induced by L-carnitine}

Addition of L-carnitine $\left(10^{-7}\right.$ to $\left.10^{-3} \mathrm{M}\right)$ to aortic rings precontracted with phenylephrine $\left(3 \times 10^{-7}\right.$ and $10^{-6} \mathrm{M}$ for WKY and SHR, respectively) elicited endothelium-dependent relaxation $(P<0.01)$ (Figure 1). The maximal re-

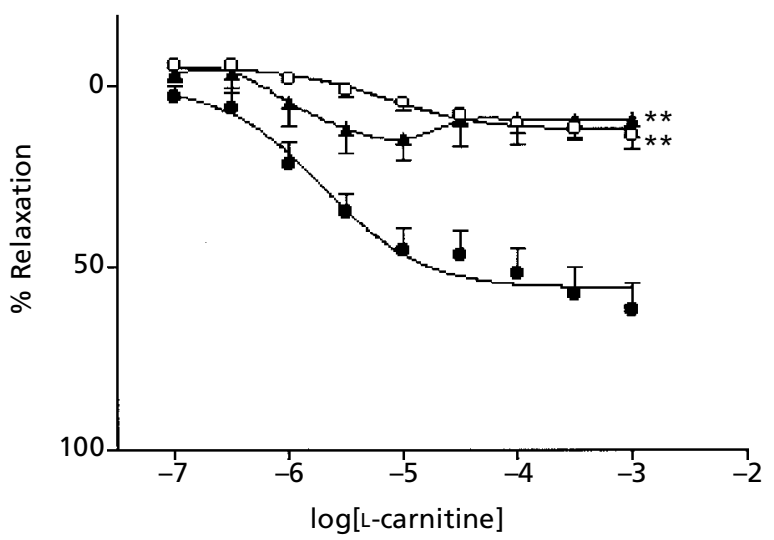

Figure 1 Effect of L-carnitine $\left(10^{-7} \mathrm{M}\right.$ to $\left.10^{-3} \mathrm{M}\right)$ in aortic rings from SHR ( $n=6$ in each case, mean \pm s.e.m.) precontracted by phenylephrine. Control intact endothelium; $\bigcirc$, denuded arteries; $\boldsymbol{\Delta}$, in the presence of L-NOARG $3 \times 10^{-5}$ M. ${ }^{* *} P<0.01$ vs control with endothelium. 
laxant effect of L-carnitine in intact aortic rings was 36.64 \pm $8.3 \%$ and $61.71 \pm 7.6 \%$ for WKY and SHR, respectively.

\section{Effect of nitric oxide synthase inhibition}

To test whether nitric oxide is involved in the endotheliumdependent relaxation to L-carnitine, the effect of nitric oxide synthase inhibitor L-NOARG $\left(3 \times 10^{-5} \mathrm{M}\right)$ was studied. In these conditions, L-NOARG completely inhibited endothelium-dependent relaxation in aortic rings from normotensive rats. Pre-incubation with L-NOARG also inhibited L-carnitine-induced relaxation in arteries obtained from SHR $(P<0.01)$. However, in the SHR aortic rings, at L-carnitine concentrations in the range $10^{-6}$ to $10^{-5} \mathrm{M}$ an L-NOARG-resistant relaxant effect remained (Figure 1).

\section{Involvement of prostanoids in the effect of L-carnitine}

The presence of the cyclooxygenase inhibitor indometacin $\left(10^{-5} \mathrm{M}\right)$ did not affect endothelium-dependent relaxation in either WKY or SHR aortic rings. When both nitric oxide synthase and cyclooxygenase were blocked together, the LNOARG-resistant relaxation in SHR aortic rings was inhibited (Figure 2).

The effects of synthetase inhibitor-thromboxane $\mathrm{A}_{2} /$ prostaglandin $\mathrm{H}_{2}$ receptor antagonist Ro $68070\left(10^{-4} \mathrm{M}\right)$ and thromboxane $\mathrm{A}_{2}$ / prostaglandin $\mathrm{H}_{2}$ receptor antagonist ICI 192,605 $\left(10^{-5} \mathrm{M}\right)$ were also tested. Both Ro 68070 and ICI 192,605 were able to significantly inhibit the endothelial relaxant response to L-carnitine in SHR arteries (Figure 3). When testing the combination of L-NOARG plus Ro 68070, the results obtained were the same as those observed with L-NOARG plus indometacin.

As shown in Figure 4, the prostacyclin synthetase inhibitor, tranylcipromine $\left(10^{-4} \mathrm{M}\right)$, did not have any signifi-

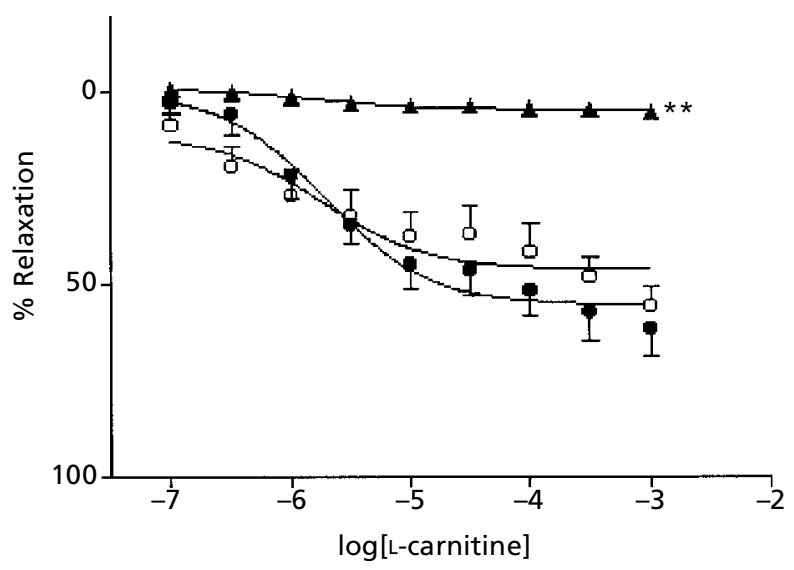

Figure 2 Effect of L-carnitine $\left(10^{-7} \mathrm{M}\right.$ to $\left.10^{-3} \mathrm{M}\right)$ in aortic rings from SHR ( $\mathrm{n}=6$ in each case, mean \pm s.e.m.) precontracted by phenylephrine. Control intact endothelium; $O$, in the presence of indometacin $10^{-5} \mathrm{M} ; \boldsymbol{\Delta}$, in the presence of indometacin $10^{-5} \mathrm{M}$ plus LNOARG $3 \times 10^{-5}$ M. ${ }^{* *} P<0.01$ vs control with endothelium.

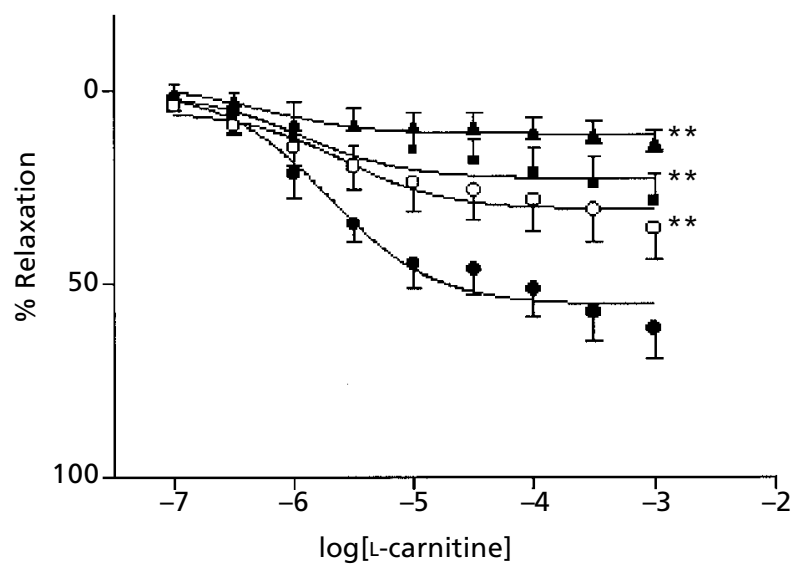

Figure 3 Effect of L-carnitine $\left(10^{-7} \mathrm{M}\right.$ to $\left.10^{-3} \mathrm{M}\right)$ in aortic rings from SHR ( $\mathrm{n}=6$ in each case, mean \pm s.e.m.) precontracted by phenylephrine. Control intact endothelium; $\bigcirc$, in the presence of Ro $6807010^{-4} \mathrm{M} ; \boldsymbol{\Delta}$, in the presence of Ro $6807010^{-4} \mathrm{M}$ plus L-NOARG $3 \times 10^{-5} \mathrm{M} ; \boldsymbol{\square}$, in the presence of ICI $192,60510^{-5} \mathrm{M}$. ${ }^{* *} P<0.01$ vs control with endothelium.

cant effect on concentration-response curves to L-carnitine. Pre-incubation with tranylcipromine plus L-NOARG did not affects the results obtained with L-NOARG alone.

\section{Discussion}

Carnitine has sometimes been beneficial as a therapeutic agent. Examples include cardiac myopathies and peripheral arterial disease (Ferrari et al 1992), and improving the walking capacity in patients with peripheral vascular disease (Brevetti et al 1992). In animal models, L-carnitine and its derivatives have shown some beneficial effect such as protection against the development of vascular lesions in peripheral arterial insufficiency induced by intra-arterial injection of sodium laurate (Corsico et al 1993), the prevention of progression of atherosclerotic lesions (Spagnoli et al 1995) and age-dependent rise of plasma total cholesterol, triglycerides and uric acid of SHR (Rauchová et al 1998) and the reduction in polyploid cells also in SHR (Mauriello et al 1996). However, the mechanism of action implicated in some of the therapeutic applications of Lcarnitine is still unclear.

The aim of this study was to investigate the vasodilatory effect of L-carnitine on isolated thoracic aorta from spontaneously hypertensive rats (SHR) and their normotensive genetic control Wistar Kyoto (WKY) rats. The results provide direct evidence of the involvement of endothelium in the concentration-dependent vasorelaxation induced by L-carnitine. Most of this endothelium-dependent effect seems to be mediated by nitric oxide because in the presence of L-NOARG, the inhibitor of nitric oxide synthesis, the relaxation to L-carnitine was significantly diminished compared with that of intact arteries from both WKY rats and SHR. The response of arteries in the presence of LNOARG was similar to that of denuded arteries. However, 


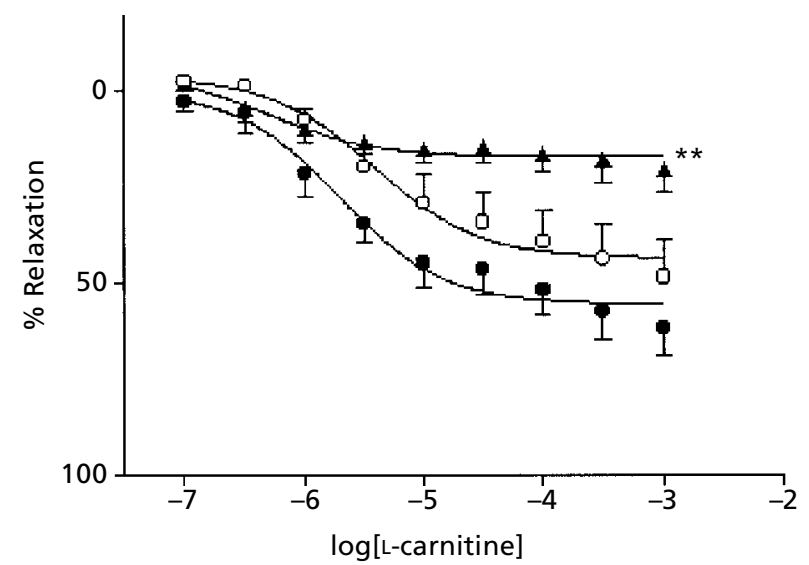

Figure 4 Effect of L-carnitine $\left(10^{-7} \mathrm{M}\right.$ to $\left.10^{-3} \mathrm{M}\right)$ in aortic rings from SHR ( $n=6$ in each case, mean \pm s.e.m.) precontracted by phenylephrine. Control intact endothelium; $\bigcirc$, in the presence of tranylcipromine $10^{-4} \mathrm{M} ; \boldsymbol{\Delta}$, in the presence of tranylcipromine $10^{-4} \mathrm{M}$ plus L-NOARG $3 \times 10^{-5}$ M. $* * P<0.01$ vs control with endothelium.

SHR aortic rings showed an L-NOARG-resistant relaxant effect in response to low concentrations of L-carnitine, indicating that the production of nitric oxide was involved in mediating the vasodilatory effects of L-carnitine but it did not seem to be the only endothelial factor released by Lcarnitine addition. In contrast, the cyclooxygenase inhibitor, indometacin, did not affect the endothelium-dependent response to L-carnitine. However, exposure to indometacin plus L-NOARG resulted in a larger inhibitory effect than L-NOARG alone, abolishing completely the response of intact arteries to L-carnitine, removing the remaining effect. These data led us to think that the vasodilator properties of L-carnitine might involve the participation of vasoactive products from cyclooxygenase, endothelial relaxant or vasoconstrictor factors in addition to nitric oxide.

To verify the nature of endothelial products from the cyclooxygenase possibly involved in the vasodilator properties of L-carnitine, the presence of a prostacyclin synthetase inhibitor did not significantly affect the concentration-response curve. When the same inhibitor was used in addition to L-NOARG, the result was similar to that obtained in the presence of indometacin plus L-NOARG, suggesting that prostaglandin $\mathrm{I}_{2}$ could be involved, but its effect was only obvious when nitric oxide synthesis was blocked. Incubation with Ro 68070 and ICI 192,605 significantly decreased the sensitivity and maximal relaxation to L-carnitine in arteries from SHR rats. Taken together, these data suggest that L-carnitine could prevent the vasoconstrictor action of cyclooxygenase endothelial products acting on the thromboxane $\mathrm{A}_{2}$ / prostaglandin $\mathrm{H}_{2}$ receptor. This observation could help explain how L-carnitine was more effective in relaxing arteries from hypertensive rats than from normotensive rats since the release of this endothelium-dependent contracting factor (EDCF) (including endoperoxides and thromboxane $\mathrm{A}_{2}$ ) explains the abnormal relaxations (Auch-Schwelk et al 1992) and contractions to acetylcholine (Auch-Schwelk et al 1990) observed in the aorta and small resistance arteries of the
SHR. The EDCF released from the hypertensive endothelium interacts chemically with nitric oxide, and both mediators inactivate each other (Ito et al 1991; AuchSchwelk et al 1992). Such a chemical interaction explains the blunting of endothelium-dependent relaxations, despite a normal ability of the endothelial cells to release endothelium-derived relaxing factors (Vanhoutte 1996). This larger release of prostaglandin $\mathrm{H}_{2}$ or thromboxane $\mathrm{A}_{2}$ in the SHR may result from a greater production $(\mathrm{Ge}$ et al 1995). On the other hand, oxidative stress can accompany hypertension in many models, including the SHR (Wilcox 2002). It has been shown that hypertension leads to enhanced superoxide production in the vasculature (Kojda et al 1999). Therefore, we cannot discard the possibility that carnitine might also possess beneficial effects on superoxide anion production in addition to nitric oxide bioavailability.

\section{Conclusion}

This study provides evidence of a vascular relaxation in response to L-carnitine in the aorta of hypertensive rats. The mechanism appeared mostly to be mediated by endothelial production of nitric oxide but also could involve prevention of the action of cyclooxygenase endothelial products acting on $\mathrm{TXA}_{2} / \mathrm{PGH}_{2}$ receptors without discarding the possibility that carnitine might also possess beneficial effects on superoxide anion production. These findings in relation to endothelial function might help to better understand the beneficial cardiovascular effects of L-carnitine.

\section{References}

Alvarez de Sotomayor, M., Pérez-Guerrero, C., Herrera, M. D., Marhuenda, E. (2001) Effect of simvastatin on vascular smooth muscle responsiveness: involvement of $\mathrm{Ca}^{2+}$ homeostasis. Eur. J. Pharmacol. 415: 217-224

Arsenian, M. A. (1997) Carnitine and its derivatives in cardiovascular disease. Prog. Cardiovasc. Dis. 40: 265-286

Auch-Schwelk, W., Katusic, Z. S., Vanhoutte, P. M. (1990) Thromboxane A2 receptor antagonists inhibit endothelium-dependent contractions. Hypertension 15: 699-703

Auch-Schwelk, W., Katusic, Z. S., Vanhoutte, P. M. (1992) Nitric oxide inactivates endothelium-derived contracting factor in the rat aorta. Hypertension 19: 442-445

Bartels, G. L., Remme, W. J., Pillay, M. (1994) Effects of L-propionylcarnitine on ischemia-induced myocardial dysfunction in men with angina pectoris. Am. J. Cardiol. 74: 125-130

Bartels, G. L., Remme, W. J., den Hartog, F. R., Wielenga, R. P., Kruijssen, D. A. (1995) Additional antiischemic effects of longterm L-propionylcarnitine in anginal patients treated with conventional antianginal therapy. Cardiovasc. Drugs Ther. 9: 749-753

Brevetti, G., Perna, S., Sabba, C., Rossini, A., Scotto di Uccio, V., Berardi, E., Godi, L. (1992) Superiority of L-propionylcarnitine vs L-carnitine in improving walking capacity in patients with peripheral vascular disease, an acute, intravenous, double-blind, crossover study. Eur. Heart J. 13: 251-255

Corsico, N., Nardone, A., Lucreziotti, M. R., Spagnoli, L. G., Pesce, D., Aureli, T., Di Cocco, M. E., Miccheli, A., Conti, F., Arrigoni Martelli, E. (1993) Effect of propionyl-L-carnitine in a rat model of 
peripheral arteriopathy, a functional, histologic, and NMR spectroscopic study. Cardiovasc. Drugs Ther. 7: 241-251

Digiesi, V., Palchetti, R., Cantini, F. (1989)The benefits of L-carnitine therapy in essential arterial hypertension with diabetes mellitus type II. Minerva Med. 80: 227-231

Digiesi, V., Cantini, F., Bisi, G., Guarino, G., Brodbeck, B. (1994) Lcarnitine adjuvant therapy in essential hypertension. Clin. Ter. 144: 391-395

Ferrari, R., Di Mauro, S., Sherwood, G. (eds) (1992) L-carnitine and its role in medicine, from function to therapy. Academic Press, London, pp 72-77

Fritz, I. B., Arrigoni-Martelli, E. (1993) Sites of action of carnitine and its derivatives on the cardiovascular system, interactions with membranes. Trends Pharmacol. Sci. 14: 355-360

Ge, T., Hughes, H., Junquero, D. C., Wu, K. K., Vanhoutte, P. M., Boulanger, C. M. (1995) Endothelium-dependent contractions are associated with both augmented expression of prostaglandin $\mathrm{H}$ synthase-1 and hypersensitivity to prostaglandin $\mathrm{H} 2$ in the SHR aorta. Circ. Res. 76: 1003-1010

Ito, T., Kato, T., Iwama, Y., Muramatsu, M., Shimizu, K., Asano, H., Okumura, K., Hashimoto, H., Satake, T. (1991) Prostaglandin $\mathrm{H} 2$ as an end othelium-derived contracting factor and its interaction with endothelium-derived nitric oxide. J. Hypertens. 9: 729-736

Kojda, G., Harrison, D. (1999) Interactions between NO and reactive oxygen species: pathophysiological importance in atherosclerosis, hypertension, diabetes and heart failure. Cardiovasc. Res. 43: 562-571

Mancini, M., Rengo, F., Lingetti, M., Sorrentino, G. P., Nolfe, G. (1992) Controlled study on the therapeutic efficacy of propionyl-Lcarnitine in patients with congestive heart failure. Arzneimittelforschung. 42: 1101-1104
Mauriello, A., Sangiorgi, G., Orlandi, A., Schiaroli, S., Perfumo, S., Spagnoli, L. G. (1996)Effect of long-term treatment with propionylL-carnitine on smooth muscle cell polyploidy in spontaneously hypertensive rats. Hypertension 28: 177-182

Mondillo, S., Faglia, S., D’Aprile, N., Mangiacotti, L., Campolo, M. A., Agricola, E., Palazzuoli, V. (1995) Therapy of arrhythmia induced by myocardial ischemia. Association of L-carnitine, propafenone and mexiletine. Clin. Ter. 146: 769-774

Rauchová, H., Dobesova, Z., Drahota, Z., Zicha, J., Kunes, J. (1998) The effect of chronic L-carnitine treatment on blood pressure and plasma lipids in spontaneously hypertensive rats. Eur. J. Pharmacol. 342: 235-239

Rizzon, P., Biasco, G., Di Biase, M., Boscia, F., Rizzo, U., Minafra, F., Bortone, A., Siliprandi, N., Procopio, A., Bagiella, E. (1989) High doses of L-carnitine in acute myocardial infarction, metabolic and antiarrhythmic effects. Eur. Heart J. 10: 502-508

Sethi, R., Dhalla, K. S., Ganguly, P. K., Ferrari, R., Dhalla, N. S. (1999) Beneficial effects of propionyl L-carnitine on sarcolemmal changes in congestive heart failure due to myocardial infarction. Cardiovasc. Res. 42: 607-615

Spagnoli, L. G., Orlandi, A., Marino, B., Mauriello, A., De Angelis, C., Ramacci, M. T. (1995) Propionyl-L-carnitine prevents the progression of atherosclerotic lesions in aged hyperlipemic rabbits. Atherosclerosis 114: 29-44

Tatlican, O., Kalaycioglu, S., Gokgoz, L., Oktar, L., Oz, E., Soncul, H., Sinci, V., Turkozkan, N., Yener, A., Ersoz, A. (1998) The dosedependent effects of L-carnitine in myocardial protection in normothermic ischemia. Cardiovasc. Surg. 6: 145-148

Vanhoutte, P. M. (1996) Endothelial dysfunction in hypertension. J. Hypertens. 14 (Suppl. 5): S83-S93

Wilcox, C. S. (2002) Reactive oxygen species: roles in blood pressure and kidney function. Curr. Hypertens. Rep. 4: 160-166 